DOI 10.37882/2223-2982.2021.06.27

\title{
РЕЧЕВАЯ АГРЕССИЯ КАК РИТОРИЧЕСКАЯ СТРАТЕГИЯ В АНГЛОЯЗЫЧНОМ ПАРЛАМЕНТСКОМ ДИСКУРСЕ
}

\section{SPEECH AGGRESSION AS A RHETORICAL STRATEGY IN ENGLISH-LANGUAGE PARLIAMENTARY DISCOURSE}

\section{O. Litvyak}

Summary: This scientific article characterizes speech aggression as a rhetorical strategy in parliamentary discourse. When studying the parliamentary discourse, such a rhetorical strategy as verbal aggression was revealed. Speech aggression in the form of invective, i.e., denigrating the opponent through the text addressed to him, requires careful study within the framework of institutional discourses. Speech aggression refers to the use of language to express hostility and rejection of an opponent. The study identified such means of speech aggression as negativism, metaphor, irony, and neologisms. The most common means of speech aggression is negativism. By helping to create a contemptuous tone and causing a depressed state, it is able to deprive an informational publication of impartiality and objectivity, while at the same time helping to argue the author's position. These language tools create a negative emotional background and style that corresponds to the intellectual and emotional needs of the addressee, and destroy the neutral background of the message of facts. The least common means are neologisms. When studying the use of this language tool in the English-language parliamentary discourse, it was revealed that in sentences with the use of neologisms there is a negative assessment of the word invented by the author and its adverse psychological impact on the audience.

Keywords: parliamentary discourse, speech aggression, press, neologism, negative emotional background.
Литвяк Олеся Валерьевна

К.филол.н., доцент, Крымский инженерно-педагогический университет имени Февзи Якубова, Симферополь ole.litviak@yandex.ru

Аннотация: В данной научной статье характеризуется речевая агрессия как риторическая стратегия в парламентском дискурсе. При изучении парламентского дискурса была выявлена такая риторическая стратегия, как речевая агрессия. Речевая агрессия в инвективной форме, т.е. очернение оппонента посредством адресованного ему текста, требует тщательного изучения в рамках институциональных дискурсов. Под речевой агрессией понимается использование языковых средств для выражения враждебности и непринятия к оппоненту. В ходе исследования были выявлены такие средства речевой агрессии, как негативизм, метафора, ирония и неологизмы. Самым распространенным средством проявления речевая агрессии является негативизм. Помогая в создании презрительного тона и вызывая угнетённое состояние, он способен лишить информационную публикацию беспристрастия и объективности, одновременно помогая аргументировать позицию автора. Данные языковые средства создают негативный эмоциональный фон и стилистику, которая соответствует интеллектуальным и эмоциональным потребностям адресата, и разрушают нейтральный фон сообщения фактов. Наименее распространенным средством являются неологизмы. При изучении употребления данного языкового средства в англоязычном парламентском дискурсе было выявлено, что в предложениях с употреблением неологизмов присутствует негативная оценка изобретенного автором слова и его неблагоприятное психологическое воздействие на аудиторию.

Ключевые слова: парламентский дискурс, речевая агрессия, пресса, неологизм, негативный эмоциональный фон.

евание и удержание политической власти. В широком смысле, политическим дискурсом называется совокупность всех речевых актов, использующихся в политических дискуссиях, и правил публичной политики, которые проверены опытом и освещены традициями. [17, c. $43-48]$

Согласно мнению ученых, парламентский дискурс следует рассматривать с разных точек зрения. Например, с филологической - подобно любому тексту; однако это осуществляется с учетом политических и идеологических концепций, которые преобладают в сознании того, кто его интерпретирует; при анализе парламентского дискурса с социопсихолингвистической точки зрения следует определять эффективность достижения потенциальных или явных политических целей говорящего; с индивидуально-герменевтической - выявлять личностные значения автора и интерпретатора выска-
Под политическим дискурсом понимается особая разновидность дискурса, целью которой является завого дискурса $и$ особеннстей его отражения в параментской риторике, и в частности, проявление речевой агрессии в политическом дискурсе, является одной из главных проблем в настоящее время.

разновиднОСть дискурса, целью которОй является заво- 
зывания в настоящих обстоятельствах. Благодаря этому парламентский дискурс является предметом изучения различных дисциплин и его исследование взаимосвязано с изучением формы, задач и содержания выражений, которые употребляются в изучаемых политических ситуациях. [18, с. 53-59]

Целью данной научной статьи является анализ речевой агрессии как риторического приёма в англоязычном парламентском дискурсе.

\section{Анализ ^итературы}

Теоретической базой для написания данной научной статьи послужили научные труды И.М. Глуховой, Н.М. Головиной, В.А. Масловой и др.

В качестве практических источников языкового материала были проанализированы и переведены на русский язык статьи в англоязычных изданиях «CBS News», «CNN International», «Financial Times», «New York Times», «The Guardian», «The Hill Times», «The Washington Post», «Yahoo News». В текстах данных источников присутствуют критические высказывания в адрес наиболее влиятельных и популярных политиков, находящихся в центре внимания СМИ и читательской аудитории.

\section{Изложение основного материала}

Речь - средство, обладающее возможностью сильного воздействия. Данное свойство в наибольшей степени реализуется в парламентском дискурсе.

При изучении парламентского дискурса была выявлена такая риторическая стратегия, как речевая агрессия. Речевая агрессия, выраженная в форме гневного выступления против определенного человека, очернения оппонента посредством адресованного ему текста, требует тщательного изучения в рамках институциональных дискурсов. Несмотря на неприятие и осуждение проявлений речевой агрессии в повседневном общении, в институциональном взаимодействии растет популярность речевой агрессии в конфликтных дискурсах.

Большая часть зарубежных исследователей следуют согласно лингвистическому подходу для изучения речевой агрессии: Any sentence or phrase standing alone and judged to be a reprimand, harsh, command, tattle, tease, insult, rejection, hostile assertion of ownership or priority, callous factual statement, accusation, criticism, obscenity or other expletives.[15, с. 62-70] -Любое предложение или фраза, стоящие отдельно и оцениваемые как выговор, грубость, приказ, болтовня, дразнить, оскорбление, отказ, враждебное утверждение собственности или приоритета, бессердечное фактическое утверждение, обвинение, критика, непристойность или другие руга-
тельств.[Перевод авторов -О.Л., А.М.] В качестве базового определения чаще всего используется определение, сформулированное Д. Инфанте, который является автором «Современной теории коммуникации»: Verbal aggressiveness is a predisposition to attack the selfconcept of others and is associated with name-calling, the use of threats, and ultimatums, negativity, resentment, and suspicion. It is considered a negative, destructive form of communication. [15, с. 62-70] - Вербальная агрессивность - это предрасположенность к нападкам на я-концепцию других и связана с обзывательством, использованием угроз и ультиматумов, негативизмом, обидой и подозрительностью. Это считается негативной, деструктивной формой общения. [Перевод авторов -O.Л., А.М.]

Наиболее распространенным средством речевой агрессии, которое нацелено на активное воздействие на адресата, являются негативизмы, то есть стилистически сниженные слова, которые расцениваются как грубые, но тем не менее запоминающиеся и легко заменяющие уведомление на воздействие на эмоциональное состояние читателя:

North Korea is gleefully shooting missiles over Japan and splashing them into the Pacific ocean.[7] - Северная Корея радостно стреляет ракетами над Японией и выплескивает их в Тихий океан. [Перевод авторов -О.Л., А.М.]

Chillaxed V. Putin cultivates strongman persona with holiday adventures. [1] - В. Путин даже во время отдыха демонстрирует образ сильного лидера. [Перевод авторов -О.Л., А.М.]

It would legitimize great power spheres of influence, encourage further aggression by Russia and others, while recognizing Putin's false claim to be a defender of Western civilization against terrorism. [2] - Это бы узаконило сферы влияния великих держав, воодушевило бы Россию и другие страны на дальнейшие агрессивные действия, а также подтвердило бы лживые заверения Путина о защите западной цивилизации от терроризма. [Перевод авторов -О.Л., А.М.]

Donald Trump is very proud of his unpredictability. The US president likes to boast that - unlike Barack Obama - he has no intention of signaling his plans to the world. [4] - Дональд Трамп очень гордится своей непредсказуемостью. Президент США любит хвастаться, что - 8 отличие от Барака Обамы - он не намерен сигнализировать миру о своих планах. [Перевод авторов -О.Л., А.М.]

"He built his political career around a tedious catchphrase about his willingness to fire losers. [13] - $\mathrm{OH}$ nостроил свою политическую карьеру на нудной фразе о своей готовности увольнять неудачников. [Перевод авторов -O.Л., А.M.]

President Trump called Kim Jong-un "Rocket Man" and threatens to "totally destroy North Korea." Mr. Kim called Mr. Trump "a mentally deranged U.S. dotard" and threatens to "definitely tame" him with "fire". [7] — Пpe- 
зидент Трамп назвал Ким Чен Ына «Человеком-ракетой» и угрожает «полностью уничтожить Северную Корею». Господин Ким назвал господина Трампа «психически ненормальным американским долларом» и угрожает «определенно приручить» его «огнем».[Перевод авторов -О.Л., А.М.]

But Trump took to bragging about the stock markets new height. [6] - Но Трамп стал хвастаться новой высотой фондовых рынков.[Перевод авторов -О.Л., А.М.]

They are making the intellectual case for a man who is the ultimate anti-intellectual. [10] - Они делают интеллектуальное обоснование для человека, который является абсолютно антиинтеллектуальным. [Перевод авторов -О.Л., А.М.]

В исследуемых примерах использованы лексемы gleefully, unpredictability, оценочный компонент которых выражает субъективное отношение автора; негативизмы aggression, anti-intellectual, dictator, false, loser, resentment, которые представляют собой убедительные невыраженные суждения. Приведенные языковые средства создают негативный эмоциональный фон и стилистику, которая соответствует интеллектуальным и эмоциональным потребностям адресата, и разрушают нейтральный фон сообщения фактов. Просторечное слово chillaxed и жаргонные выражения dizzying, flipflops не только выполняют роль негативной оценки, но и способствуют установлению доверия к автору со стороны читателя и помогают манипулировать его сознанием.

В следующих рассмотренных примерах метафора является средством создания негативных образов, которое вызывает насмешку или отвращение к объекту критики, и одновременно помогает сводить к минимуму ответственность автора в случае буквальной интерпретации его статьи.

Mr. Mugabe mocked Mr. Trump as a "giant gold Goliath" and said other nations were "embarrassed if not frightened" by his statements about North Korea. [5] Господин Мугабе высмеял господина Трампа как «гигантского золотого Голиафа» и сказал, что другие страны были «смущены, если не напуганы» его заявлениями о Северной Корее. [Перевод авторов -О.Л., А.М.]

Over the past week, Trump's anger has boiled over. [11] - за последнюю неделю гнев Трампа вскипел. [Перевод авторов -О.Л., А.М.]

The deputy attorney general R. Rosenstein - overseeing the Russia saga in lieu of Sessions. [8] - Заместитель генерального прокурора Р. Розенштейн - курирует российскую сагу вместо сессий. [Перевод авторов -О.Л., А.М.]

In addition to his more bellicose words, Trump offered a note of thanks to Russia and China for support- ing a recent round of stronger sanctions. [9] $-B$ дополнение к свочм более воинственным словам Трамп выразил благодарность России и Китаю за поддержку недавнего раунда ужесточения санкций. [Перевод авторов -О.Л., А.М.]

Военная лексика adversaries allies, annexation, enemy, advance, target оказывает содействие в создании у читателя впечатление бескомпромиссной, масштабной борьбы с продуманной политикой, которая ведется другими государствами в отношении США, и показывает, какому сильному врагу противостоит страна. Использование местоимений we, our помогают объединить отправителя и получателя сообщения, а также создать иллюзию согласия и единства мнений читателя и автора. Лексемы bluntly, boiled, dimly, buy and sell funerals, festival, hate, gleefully, medieval, post mortems, saga, scrap, sparked, unworthy, которые используются в рассмотренных примерах, служат эффективным средством выражения субъективного возмущения и однозначно негативной оценки происходящих событий. Книжные слова bellicose, vanquished вносят негативную оценку в описание событий и характеризуют политиков как не совсем адекватных людей, оторванных от реалий современной жизни.

В достаточной степени в англоязычных печатных СМИ встречается такое средство выражения речевой агрессии, как ирония или слова, контекстуальный смысл которых не совпадает с прямым значением:

Each week Donald Trump seems to make more news than most presidents do in a lifetime. [12] - Каждую неделю Дональд Трамп, кажется, делает больше новостей, чем большинство президентов за всю свою жизнь. [Перевод авторов -О.Л., А.М.]

After his rapturous welcome and a chorus "USA! USA!" the President boasted that the stock market was at an all-time hight. [14] - После его восторженного приветствия и хора «США! США!» Президент хвастался, что фондовый рынок находится на рекордно высоком уровне. [Перевод авторов -О.Л., А.М.]

Each Trump rally is a slickly choreographed cavalcade of God, the military, patriotic politicians, baby boomer rock and this magic in which a New York billionaire sells himself as a working class hero. [14] - Каждый митинг Трампа это ловко поставленная кавалькада Бога, военных, патриотических политиков, бэби-бума и этой магии, в которой нью-йоркский миллиардер продает себя как герой рабочего класса. [Перевод авторов -О.Л., А.М.]

The costs of his unpredictability are becoming clear. [4] - (Cтоимость его непредсказуемости становится очевидной). [Перевод авторов -О.Л., А.М.]

Meanwhile, Trump could do what Putin may want most of all. [3] - (Между тем Трамп мог бы сделать то, чего больше всего хочет Путин). [Перевод авторов -О.Л., А.М.] ... stop the maddening American habit of insisting that 
human rights are a universal norm. [3] - ... прекратите сводящую с ума американскую привычку настаивать на том, что права человека являются универсальной нормой. [Перевод авторов -О.Л., А.М.]

В качестве редко используемого, однако достаточно эффективного средства выражения речевой агрессии отмечен неологизм в следующем примере: They are building a Trump-Centric Movement. But don't call it Trumpism [10] - Они строят движение, ориентированное на Трампа. Но не называйте это трампизмом. [Перевод авторов -О.Л., А.М.]

В рассмотренном примере проиллюстрирована негативная оценка изобретенного автором слова и его неблагоприятное психологическое воздействие на аудиторию. Причиной возникновения неологизма «трампизм» является потребность в новой социально-политической действительности. Поскольку авторское отношение к этой реальности резко отрицательное, то и сам неоло- гизм получает негативную окраску.

\section{Выводы}

Таким образом, наиболее распространенными способами выражения речевой агрессии в англоязычных печатных СМИ являются такие средства как негативизмы, метафора, ирония и неологизм. Данные методы выражения способствуют создания негативного эмоционального настроения у читателя, чувства единства между читателем и автором. Самым распространенным средством проявления речевая агрессии является негативизм. Данные языковые средства создают негативный эмоциональный фон и стилистику, которая соответствует интеллектуальным и эмоциональным потребностям адресата, и разрушают нейтральный фон сообщения фактов. Наименее распространенным средством являются неологизмы, где очевидна негативная оценка изобретенного продуциентом слова и его неблагоприятное психологическое воздействие на аудиторию.

\section{ЛИТЕРАТУРА}

1. Chillaxed Vladimir Putin cultivates strongman persona with holiday adventures. - Электронный ресурс. - The Guardian: News, sport and opinion from the Guardian's global edition / Guardian News \& Media Limited or its affiliated companies [London, 2018]. - URL: https://www.theguardian.com/world/2017/ aug/06/ (дата обращения: 17.04.2021)

2. Don't Trust Trump's Vows to Keep Sanctions on Russia. - Электронный ресурс. - Yahoo News: Latest News \& Headlines/ Yahoo! Directory [New York, 2019]. URL: https://www.yahoo.com/news/don-t-trust-trump-vows-210119942.html (дата обращения: 17.04.2021)

3. Don't Trust Trump's Vows to Keep Sanctions on Russia. - Электронный ресурс. - Yahoo News: Latest News \& Headlines/ Yahoo! Directory [New York, 2019]. URL:https://ca.news.yahoo.com/don-t-trust-trump-vows-210119942.html (дата обращения: 17.04.2021)

4. Donald Trump's unpredictability is destabilising the world. - Электронный ресурс. - Financial Times: World/ The Financial Times [London, 2018]. - URL:https:// www.ft.com/content/b56c7c9c-3ecf-11e7-82b6-896b95f30f58 (дата обращения: 17.04.2021)

5. How World Leaders Reacted to Trump at the U.N. - Электронный ресурс. - New York Times: Breaking News, US News, World News and Videos / The New York Times Company. [New York, 2017]. - URL:https://www.nytimes.com/2017/09/23/ (дата обращения: 17.04.2021)

6. Note to President Trump: The stock market has hit an all-time high in 30 of the last 54 months. - Электронный ресурс. - CNN International: Breaking News, US News, World News/Warner Media [New York, 2017]. - URL:https://edition.cnn.com/2017/08/02/politics/stock-market-highs-months/index.html (дата 0бращения: 17.04.2021)

7. Rocket Man Knows Better. - Электронный ресурс. - New York Times: Breaking News, US News, World News and Videos / The New York Times Company. [New York, 2017]. - URL: https://www.nytimes.com/2017/09/23/ (дата обращения: 17.04.2021)

8. Rod Rosenstein, deputy attorney general overseeing Russia investigation, at Aspen Security Forum. - Электронный ресурс. - CBS News: Breaking news, 24/7 live streaming news/ CBS News [Washington, 2021]. - URL: https://www.cbsnews.com/news/ (дата обращения: 17.04.2021)

9. The Memo: Five takeaways from Trump's UN speech. - Электронный ресурс. - The Hill Times: People. Policy. Politics / Hill Times Publishing [0ttawa, 2021]. URL:https://thehill.com/homenews/administration (дата обращения: 17.04.2021)

10. They're Building a Trump-Centric Movement. But Don't Call It Trumpism. - Электронный ресурс. - New York Times: Breaking News, US News, World News and Videos / The New York Times Company. [New York, 2017]. - URL:https:/www.nytimes.com/2017/08/05/us/politics/building-a-trump-centric-intellectualmovement-trumpism.html (дата обращения: 17.04.2021)

11. Trump's anger boils over. - Электронный ресурс. - The Washington Post: Breaking News, World, US, DC News / The Washington Post [Washington, 2019]. - URL: https://www.washingtonpost.com/politics/ (дата обращения: 17.04.2021)

12. What Trump did this week: Puerto Rico, Las Vegas, 'Morongate' and more. - Электронный ресурс. - The Guardian: News, sport and opinion from the Guardian's global edition / Guardian News \& Media Limited or its affiliated companies. [London, 2017]. - URL: https://www.theguardian.com/us-news/2017/oct/07/ (дата обращения: 17.04.2021)

13. Why did Donald Trump turn on attorney general Jeff Sessions?. - Электронный ресурс. - The Guardian: News, sport and opinion from the Guardian's global edition / Guardian News \& Media Limited or its affiliated companies. [London, 2018]. - URL:https://www.theguardian.com/us-news/2017/jul/25/jeff-sessionsdonald-trump-feud-russia (дата обращения: 17.04.2021)

14. Why Trump still needs the love of the crowd: 'This is like medicine to him.' - Электронный ресурс. - The Guardian: News, sport and opinion from the Guardian's 
global edition / Guardian News \& Media Limited or its affiliated companies. [London, 2017]. - URL: https://www.theguardian.com/us-news/2017/aug/05/ (дата обращения: 17.04.2021)

15. Глухова, И.М. Лексико-семантические способы выражения речевой агрессии (на материале англоязычных печатных СМИ). - №12(408). - Челябинск, 2017. - C.62-70.

16. Головина, Н.М. Парламентские/непарламентские выражения: речевая агрессия как риторическая стратегия в парламентском дискурсе. - 3(41). Москва, 2019. - С.200-215.

17. Маслова, В.А. Политический дискурс: языковые игры или игры в слова? (Политическая лингвистика). - Вып. 1(24). - Екатеринбург, 2008. - С. $43-48$.

18. Чудинов, А.П. Дискурсивные характеристики политической коммуникации. - Вып. 2 (40). - Екатеринбург, 2012. - С. 53 -59.

( Л Литвяк Олеся Валерьевна (ole.litviak@yandex.ru).

Журнал «Современная наука: актуальные проблемы теории и практики»

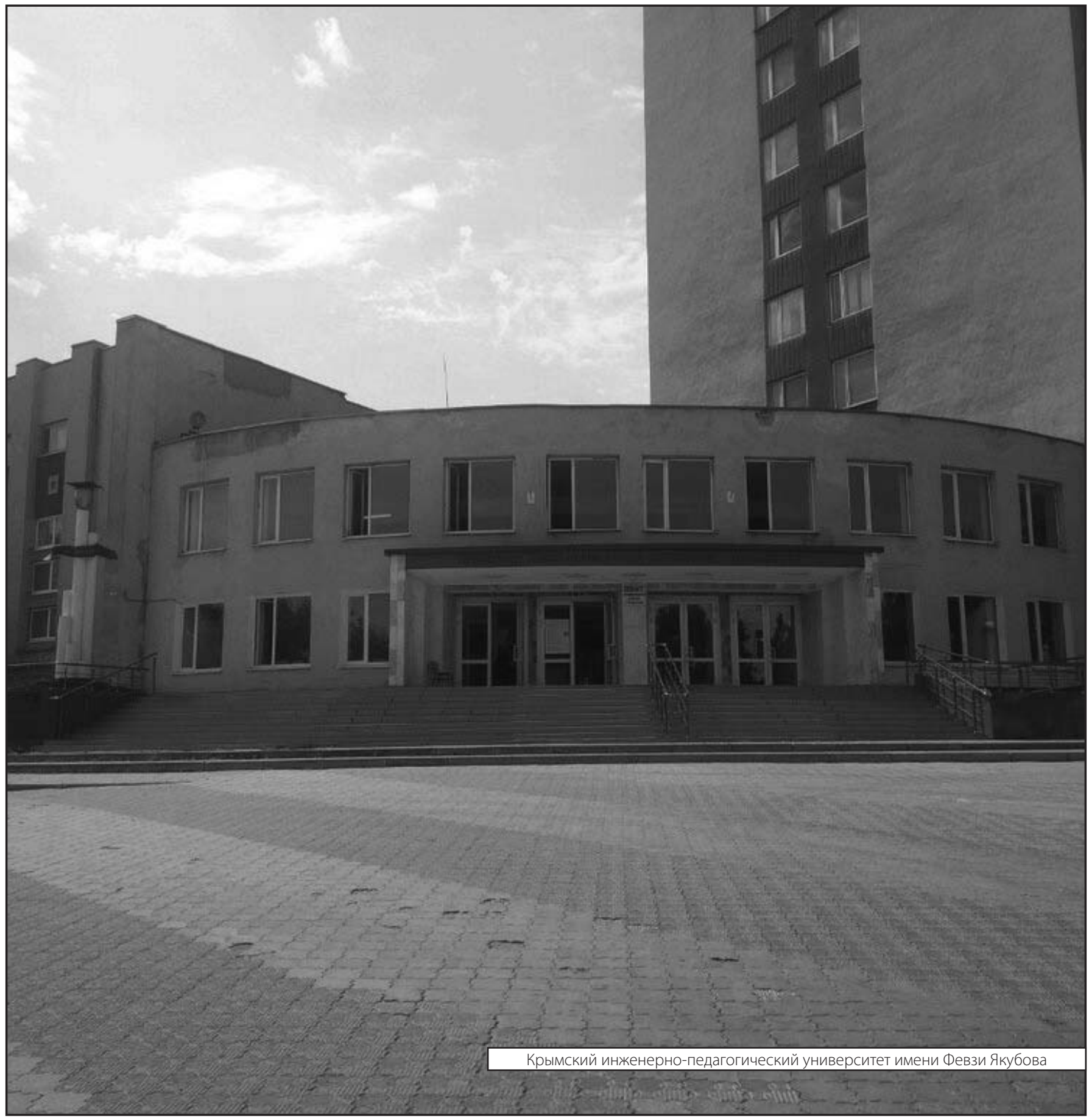

